\title{
Attenuation of Exercise Induced Asthma by Nedocromil Sodium and Sodium Cromoglycate
}

\author{
Major D G Sinclair \\ MRCP (UK), RAMC, Senior Specialist in Medicine
}

\author{
Lt Col C R Winfield
}

FRCP (Lond), RAMC, Consultant Physician

Army Chest Unit, Cambridge Military Hospital, Aldershot, Hants GU11 2 AN

SUMMARY: A randomized double blind cross over trial to compare nedocromil sodium and sodium cromoglycate with placebo in the prevention of exercise induced asthma was conducted.

Twenty asthmatics received nedocromil sodium, sodium cromoglycate or placebo via metered dose inhalers on successive days 30 minutes before exercise in a randomized order. Nedocromil sodium and sodium cromoglycate gave sufficient protection $(P<0.05)$ compared to placebo as assessed by the reduction in the maximum percentage fall in the forced expiratory volume in 1 second (FEV1). The protective effect of nedocromil sodium and sodium cromoglycate varied in individuals.

\section{Introduction}

There are a number of similarities between nedocromil sodium and sodium cromoglycate in that they are both used in the prophylaxis of asthma, and both inhibit the release of mediators of inflammation by a number of cell types ${ }^{1-3}$. There are however differences in molecular structure ${ }^{4}$.

We compared these drugs with placebo in their effect on exercise induced asthma as conflicting studies have been reported ${ }^{5-7}$.

\section{Patients, Methods and Results}

Twenty patients were studied, 18 male and 2 female, aged 17 to 28 , mean age 20.7 with reproducible exercise induced asthma. Patients taking oral or inhaled corticosteroids were excluded as were patients who had previously been treated with nedocromil sodium or sodium cromoglycate. Bronchodilator drugs were discontinued $24 \mathrm{hrs}$ prior to the start of the trial period. The study was carried out in a random double blind cross over fashion.

Measurements of forced expiratory volume in one second (FEV1) were recorded on a dry wedge spirometer (vitalograph). Each patient performed an exercise vitalograph on 3 successive days: 30 minutes before each test they received 2 metered inhalations from one of 3 pressurized aerosols labelled A, B or C in a randomized order thereby receiving placebo, $4 \mathrm{mg}$ of nedocromil sodium or $10 \mathrm{mg}$ of sodium cromoglycate. The code was known only to the hospital pharmacist until the end of the study.

Exercise testing consisted of steady state running on a treadmill at a speed of $6 \mathrm{~km}$ per hour with an incline of $10^{\circ}$ for 6 minutes, the same settings being used for all subjects. All the exercise tests were performed between 9.30 and $11.30 \mathrm{am}$. The ambient temperature range was $17-25^{\circ} \mathrm{C}$ over the trial period. Spirometry was performed prior to exercise then immediately and 1, 3,
5,7 and 9 minutes after exercise. There were no significant differences in the pre-exercise spirometry on any day.

The results of the exercise tests were expressed as the mean percentage fall in FEV1 from the baseline valued prior to exercise and analysed using a statistical mode $\widehat{\Phi}$ and analysis of variance technique appropriate for a triå of this design.

The patterns in mean FEVI measurements expresse as percentage changes from resting FEV1 levels are broadly similar after exercise for nedocromil sodium an $\$$ sodium cromoglycate with raised FEV1 levels immediately post exercise followed by a decline in FEV below the baseline up to 9 minutes after the completion of exercise (Fig 1). Both drugs attenuate the post exercise fall in FEV1 compared with placebo although the broad pattern over time is similar. Significant differences in the FEV1 response were found between the active drugs and placebo immediately and 1, 3, 5, 7 and 9 minutes after exercise $(P<0.05)$.

Examination of the percentage changes in FEV1 by active drug and subject indicates that the individual response to the drugs is variable. Five patients derived little or no benefit from sodium cromoglycate but responded well to nedocromil sodium, and in one patient the opposite applied. These differences are not consistently explained by personal characteristics, resting FEV1 measurements or by the treatment sequences.

The differences in mean FEV1 values obtained with nedocromil sodium and sodium cromoglycate were not statistically significant.

\section{Discussion}

Nedocromil sodium is the disodium salt of a pyranoquinoline dicarboxylic acid and although similar to sodium cromoglycate has a different carbon ring structure $^{4}$. 


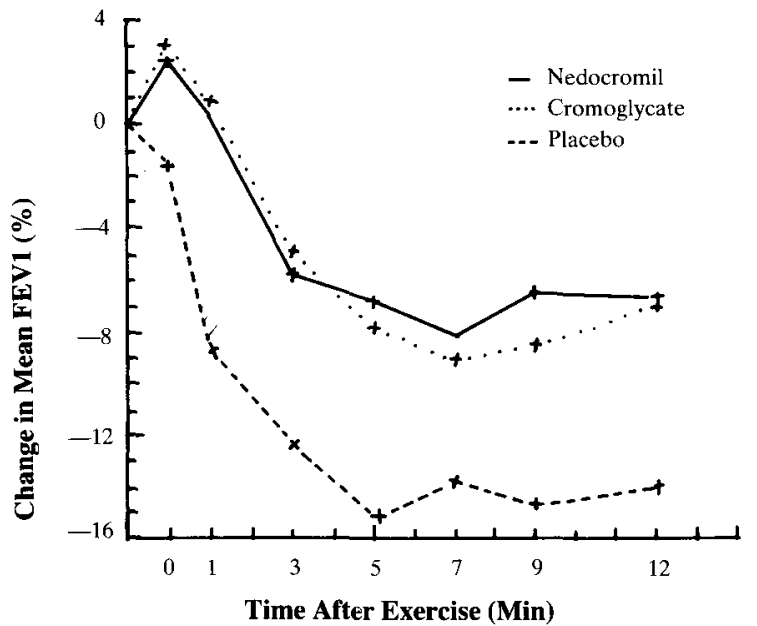

Fig 1. The effect of placebo, nedocromil sodium and sodium cromoglycate on the mean percentage falls in FEV1 after exercise in 20 patients with asthma.

This study demonstrates that $4 \mathrm{mg}$ of nedocromil sodium is more effective than placebo and is equally as effective as $10 \mathrm{mg}$ of sodium cromoglycate in preventing exercise induced asthma. Our results are in agreement with those of Magnussen ${ }^{5}$ and Konig et al $^{6}$ although the design of our study was different and we used a lower dose of sodium cromoglycate. Patel and Albazzaz ${ }^{7}$ found nedocromil sodium offered significantly higher protection compared with sodium cromoglycate in a study similar to ours. They used only $4 \mathrm{mg}$ of sodium cromoglycate thereby comparing these drugs $\mathrm{mg}$ for $\mathrm{mg}$, whereas we compared recommended twice daily doses which may explain this discrepancy. The variable individual responses to nedocromil sodium and sodium cromoglycate suggest that there may be a difference in their methods of action which could be explained by their differing molecular structure.

In conclusion both drugs modify the asthmatic $\frac{3}{\infty}$ response to exercise. If a patient shows lacks of response to one of these drugs it is recommended that the other be tried.

\section{Acknowledgements}

We are grateful to Mrs M Sims for performing the statistical analysis and to Miss $\mathrm{H}$ Blythe for typing the manuscript.

\section{REFERENCES}

1. Spry C J C, Kumaraswami V and TaI P C. The Effect of $\vec{\theta}$ Nedocromil Sodium on Secretion from Human Eosinophils. Eur J Respir Dis 1986; 69 (Suppl 147): 241- $\vec{\omega}$ 243.

2. RADFORD P G, FARRELl $M$ and RuBin R P. Effects of Cromolyn Sodium and Nedocromil Sodium on Stimulus Secretion Coupling in the Rabbit Neutrophil. Am Rev Resp Dis 1987; 135 (4): A319.

3. RiLEY P A et al. Activity of Nedocromil Sodium in Mast Cell Dependent Reactions in the Rat. Int Arch Allergy Appl Immunol 1987; 82(1): 108-110.

4. Gonzalez J P and Brogden R N. Nedocromil Sodium A Preliminary Review of its Pharmacokinetic Properties 5 and Therapeutic Efficacy in the Treatment of Reversib Obstructive Airways Disease. Drugs 1987; 34: 560-577.

5. Magnussen H. The Protective Effect of Sodium Cromoglycate (SCG) and Nedocromil Sodium on Effort Induced Bronchial Asthma. Atemw - Lungenkrkh 198\%; 12: (2nd Special Issue) 107-109.

6. Konig P, Hordvik N L and Kreutz C. The Preventi Effects and Duration of Action of Nedocromil Sodium a fad Cromolyn Sodium on Exercise Induced Asthma (EIA) Adults. J Allergy Clin Immunol 1987; 79(1): 64-68.

7. Patel K R and AlbazzaZ M K. Protective Effect of Cromolyn Sodium and Nedocromil Sodium in Exercise $\unrhd$ Induced Asthma. J Allergy Clin Immunol 1987; 79(1): 187. 